\title{
Analytical Study of Temporal Bone Pathologies and Anatomical Variations on High Resolution CT.
}

\author{
Lalit Kumar ${ }^{1}$, Ankur Malhotra ${ }^{2}$, Rajul Rastogi ${ }^{2}$, Vijai Pratap ${ }^{3}$ \\ ${ }^{1}$ Senior Resident, Department of Radio-Diagnosis, Teerthanker Mahaveer Medical College And Research Center (TMMC\&RC), Moradabad, ${ }^{2}$ Associate Professor, \\ Department of Radio-Diagnosis, Teerthanker Mahaveer Medical College And Research Center (TMMC\&RC), Moradabad, ${ }^{3}$ Professor \& Head, Department of Radio- \\ Diagnosis, Teerthanker Mahaveer Medical College And Research Center (TMMC\&RC), Moradabad.
}

\section{Abstract}

Background: High Resolution Computed Tomography (HRCT), a modification of routine CT, owing to its ability to delineate intricate osseous anatomy and admirable topographic visualization, is widely used for accurate assessment of temporal bone pathologies prior to surgical exploration. The present study was undertaken to evaluate temporal bone in diseased ears by HRCT and its importance in patient management. Subjects and Methods: This prospective study was conducted in the department of Radiodiagnosis of a large tertiary care hospital in Northern India. A total of 50 patients with clinically proven middle ear disease with hearing loss or chronic suppurative otitis media (CSOM) were enrolled into this study. All cases were evaluated with 128 slice CT scanner (Philips Medical systems, Cleveland, USA). Results: Mean age of patients in our study was $29.52 \pm 21.48$ years. Maximum patients with temporal bone pathologies had either sclerosed or under-pneumatized mastoids. Limited numbers of anatomical variations were noted with Korner's septum being the most common variation $(7.14 \%)$. Others variations included high jugular bulb $(2.86 \%)$, facial nerve dehiscence $(2.86 \%)$, labyrinthine fistula $(2.86 \%)$ and foramen tympanicum $(1.43 \%)$. Otomastoiditis was the most frequently encountered pathological condition in the study population (72.86 \%), followed by cholesteatoma (32.86 \%). Congenital malformations were seen in 10 cases $(14.29 \%)$ with type I incomplete partition (5.71\%) being the most common malformation. Conclusion: HRCT of temporal bone is useful in identifying common ear pathologies and anatomical variations prior to the surgery and thereby planning appropriate surgical approach.

Keywords: High Resolution Computed Tomography (HRCT); Temporal bone; Otomastoiditis; Cholesteatoma; Anatomical variation.

Corresponding Author: Dr Ankur Malhotra, Associate Professor, Department Of Radio-Diagnosis, Teerthanker Mahaveer Medical College and Research Center (TMMC\&RC), Moradabad.

Received: January 2019

Accepted: January 2019

\section{Introduction}

Common symptoms with ear pathologies include earache, tinnitus, vertigo, headache and ear discharge. Due to vague symptoms, many a times it is difficult for the otolaryngologist to reach a definite clinical diagnosis. Some of the middle ear diseases (e.g., inflammation and neoplastic diseases) can become serious medical problems if not identified and treated in time and may extend to involve the inner ear, brain and systems beyond. Complex anatomy of the temporal bone limits the ability of conventional radiological methods like plain radiograph to outline the details of the temporal bone, cochleo-vestibular anatomy and pathologic conditions. ${ }^{[1]}$

Computed tomography (CT) has always been the preferred imaging modality to delineate the intricate osseous anatomy and malformations of the inner ear. Multidetector row computed tomography (MDCT) is a truly three-dimensional imaging modality which has transformed from trans-axial cross sectional CT technique. High resolution computed tomography (HRCT) has the advantage of admirable topographic visualization, devoid of artifacts from superimposition of structures. It helps in accurate assessment of pathology prior to surgical exploration regarding location, extent and complication of the disease. ${ }^{[2]}$ There are various normal anatomic variants such as high jugular bulb or jugular bulb dehiscence, aberrant internal carotid artery (AICA), bulging sigmoid sinus and dehiscent facial nerve canal. These variations are usually seen as incidental imaging findings and later on may come into sight with certain surgical significance. ${ }^{[3]}$

With this background the present study was undertaken to evaluate pathologies as well as the normal anatomic variations and congenital anomalies of temporal bone by high resolution computed tomography (HRCT) and their importance in patient management. In addition, we also attempted to correlate various anatomical variations with pathologies of temporal bone and their surgical importance.

\section{Subjects and Methods}

This prospective study was conducted in the Department of Radiodiagnosis of a large tertiary care hospital in Northern India. A written informed consent of all patients was taken before enrollment in the study. Prior approval of the Institutional Ethical Committee was taken to conduct the above study. Secrecy and Confidentiality were maintained. 
A total of 50 patients with clinical suspicion of temporal bone pathology were enrolled into this study. However, patients with history of electrical device fixation at the skull base, such as cochlear implants or with history of temporal bone trauma were excluded from our study. All cases were evaluated with 128 slice CT scanner (Philips Medical systems, Cleveland, USA). Prior to performing the scan in few pediatric patients (less than six years) sedation was given. The purpose of sedation was to avoid motion artifacts and to ensure a CT scan of diagnostic quality. A thin collimation, a high spatial frequency algorithm was used with multi-planar reconstruction.

Scan parameters were as follows: $120 \mathrm{kVp}, 300 \mathrm{mAs}$, raw slice thickness $0.67 \mathrm{~mm}$, reconstructed slice thickness $0.67 \mathrm{~mm}$, window width 4000, window level 600 .

A lateral topogram was performed routinely before starting the scan. Scanning began from the lower margin of the external auditory meatus and extended upward to the arcuate eminence of the superior semicircular canal. Multiplanar reconstruction was done. The original images obtained at standard resolution were examined by using soft tissue window and bone algorithm by using special reconstruction function of the computer.

The analysis included profiling patients of different clinical history, anatomical variations, surgical follow up and pathological findings.

\section{Results}

Out of 100 temporal bones of 50 patients, pathologies were found in 70 temporal bones and 30 temporal bones were free of disease process. Mean age of patients in our study was $29.52 \pm 21.48$ years [Graph 1]. Maximum numbers of patients were in early decades of their life $(24 \%$ in age group 10-19 years and 20\% in age group $<10$ years). Equal gender distribution of temporal bone disease was noticed in our study with male to female ratio of 1:1. $20(40 \%)$ out of 50 patients had bilateral ear pathologies while rest had unilateral ear involvement. Isolated right ear involvement seen in $14(28 \%)$ patients and isolated left ear was involved in $16(32 \%)$ patients. The chief presenting symptoms [Graph 2] were hearing loss (70\%), ear discharge (56\%) and ear ache (36\%). Besides these some patients also presented with headache $(18 \%)$, vertigo $(16 \%)$, tinnitus $(12 \%, n=6)$, fever $(2 \%, n=1), 7$ th nerve palsy $(2 \%, n=1)$, and postauricular swelling (10\%).

Out of 100 mastoids of 50 patients, $48(48 \%)$ mastoids were sclerosed, $22(22 \%)$ on right side and $26(26 \%)$ on left side. Well pneumatized mastoids were $33(33 \%)$ in number, 18 (18\%) on right side and $15(15 \%)$ on left side. $19(19 \%)$ mastoids were found to be underpneumatized; 10 (10\%) on right side and $9(9 \%)$ on left side [Table 1]. Volumes of left sided mastoids were higher in comparison to right side. Mean volume of sclerosed mastoids was found to be $0.96 \pm$ $0.46 \mathrm{cc}$ (right) and $1.08 \pm 0.49 \mathrm{cc}$ (left). Mean volume of pneumatized mastoids was found to be $6.37 \perp 2.33 \mathrm{cc}$ (right) and $7.35 \pm 1.99 \mathrm{cc}$ (left). Mean volume of underpneumatized mastoids was found to be $1.74 \pm 0.47 \mathrm{cc}$ (right) and $1.77 \pm 0.41 \mathrm{cc}$ (left).
Few anatomical variations in pathological temporal bones were also found in our study [Table $2 \& 3$ ] . Korner's septum [Figure 1] was found to be the most common variation (7.14 $\%)$. Others variations were high jugular bulb (2.86\%, [Figure 2]), facial nerve dehiscence (2.86\%), labyrinthine fistula $(2.86 \%)$ and foramen tympanicum $(1.43 \%)$.

Various temporal bone pathologies were noted in our study involving middle ear (Figure 3), external ear and inner ear. Oto-mastoiditis was the most frequently encountered pathological condition $(72.86 \%)$, followed by cholesteatoma $(32.86 \%)$. All cases affected with cholesteatoma showed soft tissue density in middle ear and mastoids with erosions of adjoining bony structures [Table 41 with following incidence- ossicular chain erosion (30\%), scutum erosion (27.14\%), tegmen tympani erosion (18.57\%), erosion of facial nerve canal $(11.43 \%)$, erosion of semicircular canals $(4.21 \%)$. EAC atresia, malignant otitis externa and common cavity were least commonly seen pathologies, each involving 1 ear $(1.43 \%)$. One patient was found with bilateral retrofenestral type (cochlear) otosclerosis $(2.86 \%)$.
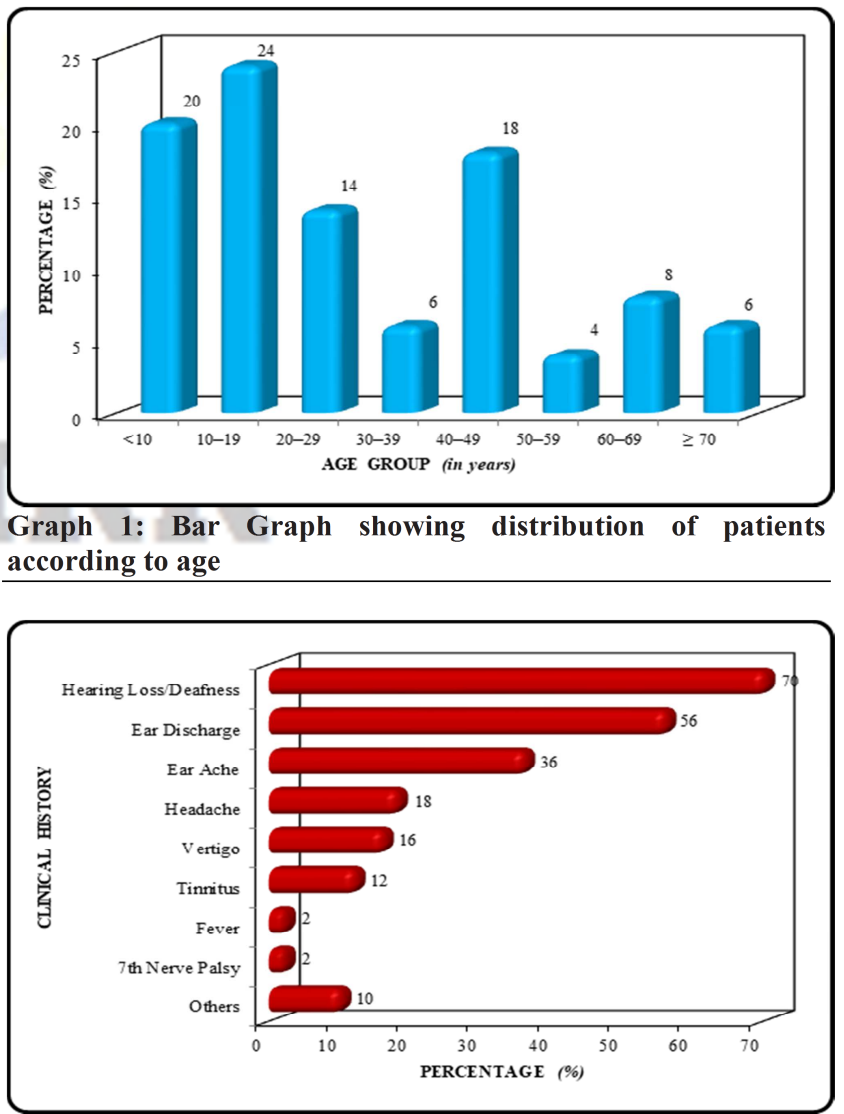

Graph 2: Distribution of patients according to the presenting symptoms $(\mathbf{n}=\mathbf{5 0})$

A total number of 10 ears were involved by congenital malformations (14.29\%) in present study [Graph 3]. Most common inner ear malformation was Type I Incomplete Partition (5.71\%) and least common was common cavity $(1.43 \%) .4$ cases of middle ear disease and 1 case of Mondini malformation had Korner's septum, 2 cases of 
Frumar et al; Jemparal Bane Pathalagies and Anattamical Variautians an Htigh Resalutian CF cholesteatoma had facial nerve dehiscence (FND) and labyrinthine fistula; 2 cases of middle ear disease had high riding jugular bulb (HRJB). The knowledge of these anatomical variations beforehand helped ENT surgeon in preoperative planning of surgical road maps [Graph 4].

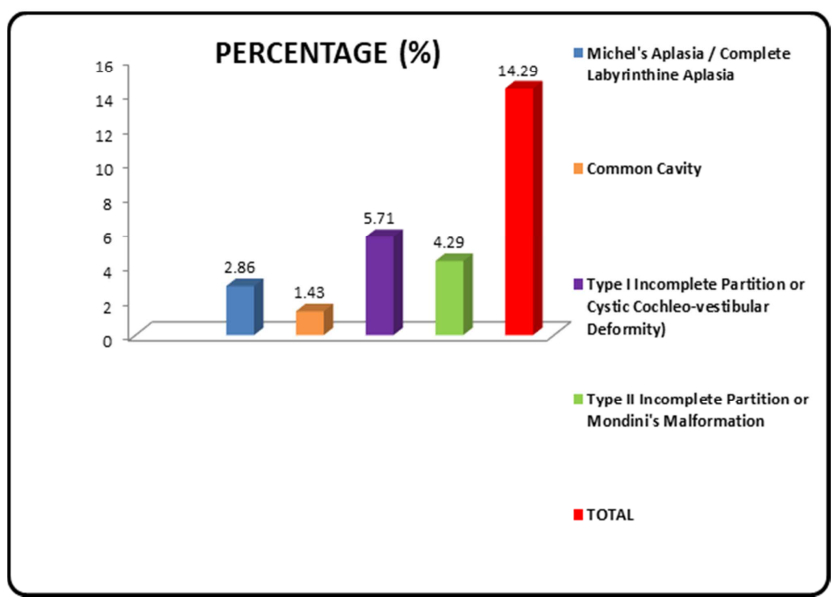

Graph 3: Bar graph showing distribution of congenital malformations of inner ear

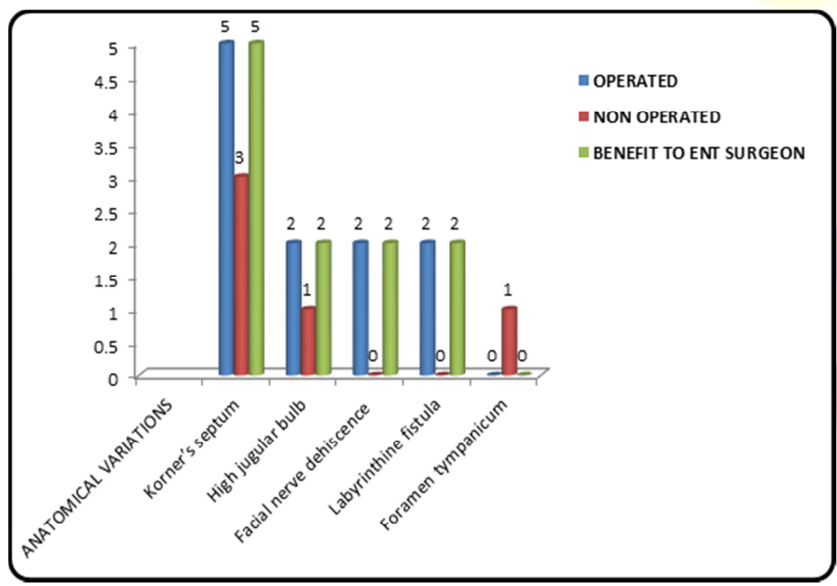

Graph 4: Bar graph showing Anatomical variations with temporal bone pathologies and benefit to surgeon.

Table 1: Correlation of mastoid pneumatization with temporal bone status.

\begin{tabular}{|c|c|c|c|c|c|}
\hline \multirow[t]{2}{*}{ Pneumatization } & \multicolumn{2}{|c|}{$\begin{array}{c}\text { Pathological } \\
\text { Temporal Bone } \\
(\mathbf{N}=70)\end{array}$} & \multicolumn{2}{|c|}{$\begin{array}{c}\text { Non Pathological } \\
\text { Temporal Bone } \\
(\mathbf{N}=\mathbf{3 0})\end{array}$} & \multirow[t]{2}{*}{$\begin{array}{c}\text { Total } \\
(\mathrm{N}=100)\end{array}$} \\
\hline & Right & Left & Right & Left & \\
\hline Sclerosed & 19 & 23 & 3 & 3 & 48 \\
\hline Pneumatized & 5 & 4 & 13 & 11 & 33 \\
\hline Underpneumatized & 10 & 9 & 0 & 0 & 19 \\
\hline
\end{tabular}

Table 2: Distribution of cases according to the anatomical variations in diseased temporal bones $(n=70)$.

\begin{tabular}{|c|c|c|}
\hline Anatomical Variations & Number Of Cases & $\begin{array}{l}\text { Percentage } \\
(\mathbf{\%})\end{array}$ \\
\hline Korner's Septum & 5 & 7.14 \\
\hline High Jugular Bulb & 2 & 2.86 \\
\hline Facial Nerve Dehiscence & 2 & 2.86 \\
\hline Labyrinthine Fistula & 2 & 2.86 \\
\hline Foramen Tympanicum & 1 & 1.43 \\
\hline Total & 12 & 17.14 \\
\hline
\end{tabular}

Table 3: Distribution of cases according to the anatomical variations in normal temporal bones $(n=30)$

\begin{tabular}{|c|c|c|}
\hline Anatomical Variations & Number Of Cases & $\begin{array}{l}\text { Percentage } \\
\mathbf{( \% )}\end{array}$ \\
\hline Korner's Septum & 3 & 10 \\
\hline High Jugular Bulb & 1 & 3.33 \\
\hline Dehiscent Jugular Bulb & 1 & 3.33 \\
\hline Total & 5 & 16.66 \\
\hline
\end{tabular}

Table 4: HRCT findings showing area involved in temporal bone pathologies $(n=70)$

\begin{tabular}{|c|c|c|}
\hline Area Involved & $\begin{array}{l}\text { Number Of } \\
\text { Patients }\end{array}$ & $\begin{array}{l}\text { Percentage } \\
\mathbf{( \% )}\end{array}$ \\
\hline Mastoid Air Cells & 56 & 80.00 \\
\hline Mesotympanum & 51 & 72.86 \\
\hline Epitympanum & 47 & 67.14 \\
\hline Hypotympanum & 42 & 60.00 \\
\hline Antrum & 38 & 54.29 \\
\hline Ear Ossicles Erosion & 21 & 30.00 \\
\hline Scutum Erosion & 19 & 27.14 \\
\hline Tegmen Erosion/Thinning & 13 & 18.57 \\
\hline Facial Nerve Canal & 8 & 11.43 \\
\hline Erosion/Thinning & & \\
\hline SCC Frosion & 3 & 4.29 \\
\hline External Ear & 3 & 4.29 \\
\hline
\end{tabular}

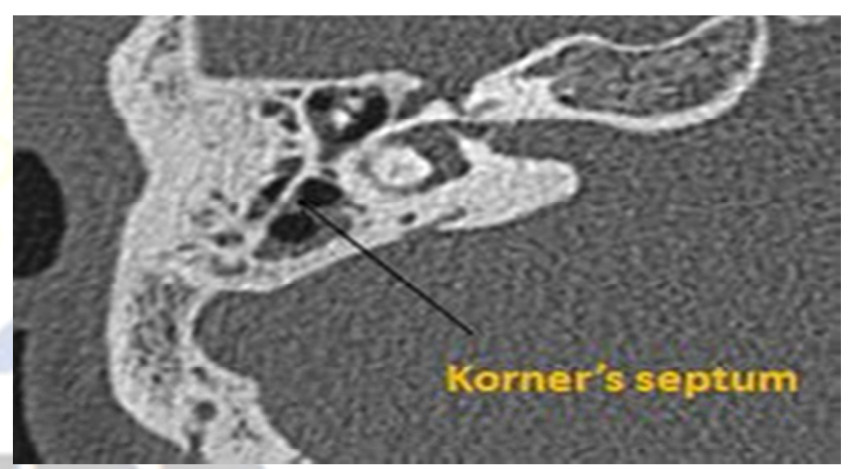

Figure 1: Axial CT scan of right temporal bone of 27 year old female showing Korner's septum ( arrow).

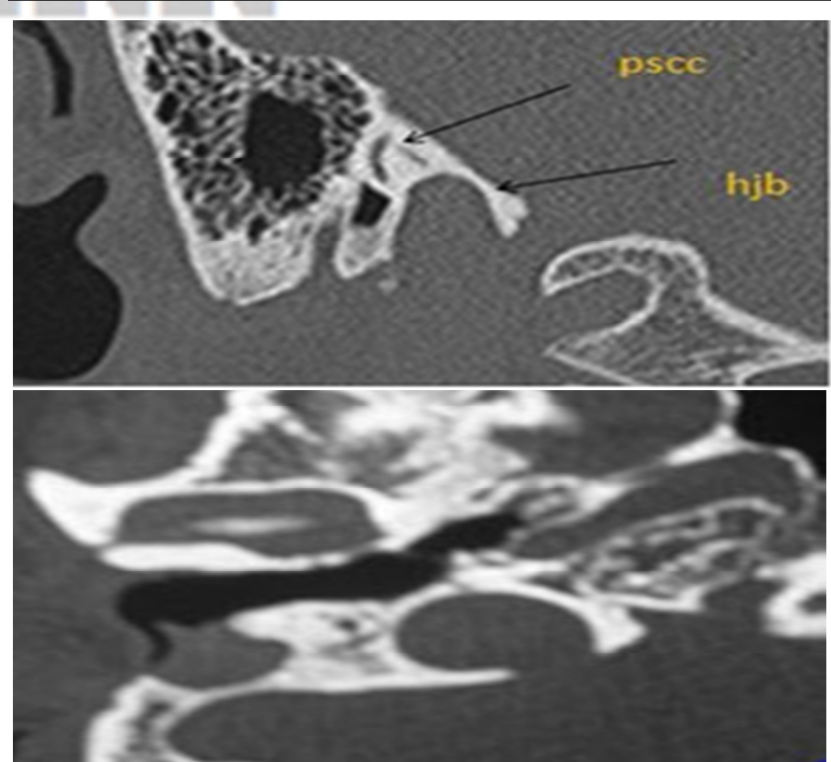

Figure 2: Coronal image (a) of right temporal bone shows high jugular bulb (hjb)above the level of posterior semicircular canal (pscc). Axial image (b) of another patient's right temporal bone shows high jugular bulb above the level of internal auditory meatus. 


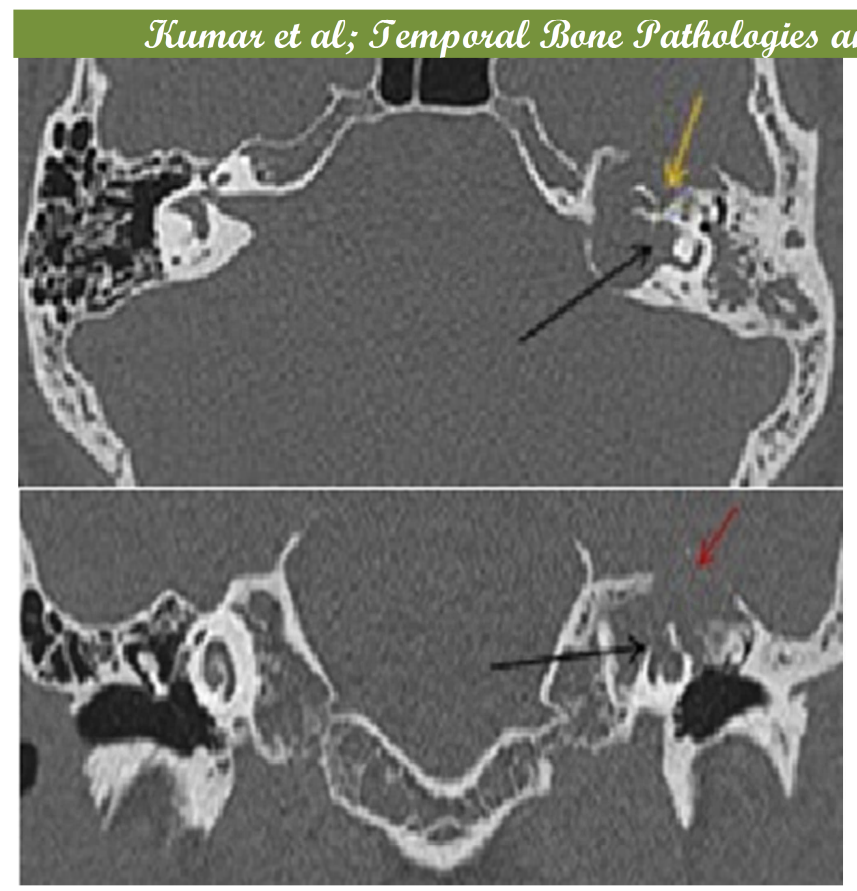

Figure 3: Axial (a) and coronal (b) images show aggressive attico-antral cholesteatoma involving petrous part of left temporal bone. There is expansion and erosion of left tegmen tympani (red arrow), labyrinthine part of left facial nerve (yellow arrow), left bony and membranous labyrinth (black arrow). Right temporal bone is normally seen.

\section{Discussion}

The application of high-resolution computed tomography (HRCT) has completely revolutionized imaging of the temporal bone and allowed the detailed assessment of complex bony anatomy and pathology. HRCT temporal bone accurately depicts bony erosion or destruction and associated soft tissue pathology. ${ }^{[4,5]}$

The varied temporal bone pathologies including inflammatory conditions, congenital inner ear malformations and normal anatomical variations were evaluated in this study by HRCT. The most common age group involved in our study was $10-19$ years (24\%) with mean patient age $( \pm$ SD) of $29.52 \pm 21.48$ years. In a study by Handi et al, ${ }^{[4]}$ and Bagul et $a 1,{ }^{[6]}$ the majority of patients belong to age group of 11-40 yrs. Thus, it can be inferred that the pathologies associated with temporal bones usually affect individuals in early decades of their life.

Hearing loss, ear discharge and earache appeared to be the most frequent presenting complaints in our patients with temporal bone pathologies; while other symptoms had variable frequency. Unilateral involvement (60\%) of temporal bone was significantly higher than bilateral disease in our study with preferential involvement of left ear $(32 \%)$. Our findings are consistent with previous studies. ${ }^{[5-7]}$ The degree of mastoid pneumatization closely depends upon the status of middle ear (diseased/normal). ${ }^{[8-9]}$ In our study, we encountered sclerosed (42 out of 48) and under pneumatized (all 19) mastoids more frequently in pathological temporal bones while non- pathological temporal bones mostly had well pneumatized mastoids (24 out of 33). Sethi et al, ${ }^{[10]}$ in their study also found a significant correlation $(p<0.05)$ between mastoid pneumatization and middle ear disease.

We also calculated volume of mastoids in cubic centimeter (cc) using volumetric analysis software (Philips intelli space 3D segmentation software) provided for computerized digital processing of HRCT. Mean volume of pneumatized mastoids in our study was found to be $6.37 \pm 2.33 \mathrm{cc}$ (right) and $7.35 \pm 1.99 \mathrm{cc}$ (left). We observed that volume of left sided mastoids were higher as compared to right sided mastoids. Our findings are in contrast to the findings of Karakas et al, ${ }^{[11]}$ who found volume of right sided mastoids higher than left. This could possibly due to racial or ethnic factors.

We found Korner's septum as the most common variation $(n=5,7.14 \%)$ in diseased temporal bones, followed by high jugular bulb ( $\mathrm{n}=2,2.86 \%)$, facial nerve dehiscence (FND) $(\mathrm{n}=2,2.86 \%)$, labyrinthine fistula $(\mathrm{n}=2,2.86 \%)$ and foramen tympanicum $(n=1,1.43 \%)$. All our cases of FND and labyrinthine fistula were associated with cholesteatoma. We also found few variations in the non pathological temporal bones $(\mathrm{n}=5,16.66 \%)$; where again Korner's septum was most common $(n=3,10 \%)$ followed by high jugular $(n=1,3.33 \%)$ and dehiscent jugular bulb $(n=1,3.33 \%)$. Our findings vary with the study by Karakas et al, ${ }^{[1]}$ who reported high jugular bulb (32\%) as the most common anatomical variation followed by Korner's septum (28\%) and facial nerve dehiscence $(12 \%)$. The incidence of foramen tympanicum in a study by Lacouta et al, ${ }^{[12]}$ was also higher (4.6\%) as compared to our study. The numbers of anatomical variations in our study population are very few, which may limit the statistical significance and comparison with the previous studies.

Majority of our patients presented with suppurative disease of middle ear and mastoids, of which oto-mastoiditis accounted for the most number of ears involved $(n=51$, $72.86 \%)$, followed by cholesteatoma ( $n=23,32.86 \%)$. These findings are comparable with the previous studies. ${ }^{[4,6]}$ The incidence of disease extent was found to be highest in epitympanum $(n=50)$, which came out to be the most frequently involved site in other studies as well; Tak et al $(n=38)$ and Vallabhaneni et al $(n=28) .{ }^{[7,13]}$ However involvement of mesotympanum, hypotympanum, antrum and mastoids in our study did not matched with above studies. Even the involvement of these regions in the studies of Tak et al, ${ }^{[7]}$ and Vallabhaneni et al, ${ }^{[13]}$ also did not match with each other. Thus, in oto-mastoiditis although the epitympanum is most frequently involved in disease process, the involvement of rest of the regions varies.

All our patients with cholesteatoma had soft tissue density in the middle ear and mastoids [Figure 3], Besides these, ossicular chain erosion (30\%) and scutum erosion $(27.14 \%)$ were the most common findings in maximum cases followed by erosion of tegmen tympani (18.57\%), erosion of facial nerve canal $(11.43 \%)$ and erosion of semicircular canals $(4.21 \%)$. Excellent correlation was found in our study regarding extent of cholesteatoma and adjoining bony erosions such as ossicular chain erosion, scutum erosion etc. which is comparable with previous studies. ${ }^{[4,14]}$

There are many syndromes with associated inner ear malformations which are described in literature. ${ }^{[15,16]}$ In our 
study, Type I Incomplete Partition accounted for most of the congenital ear malformations $(n=4,5.71 \%)$, followed by Type II Incomplete Partition or Mondini's Malformation $(\mathrm{n}=3,4.29 \%)$, and Michel's Aplasia / Complete Labyrinthine Aplasia $(n=2,2.86 \%)$. Least commonly encountered inner ear malformation was common cavity $(\mathrm{n}=1,1.43 \%)$. In a study by Joshi et al, ${ }^{[17]}$ Type II Incomplete Partition or Mondini's malformation was the most commonly seen inner ear anomaly while $\mathrm{Wu}$ et al, ${ }^{[18]}$ found large vestibular aqueduct syndrome (LVAS) as the most frequent inner ear malformation in their study. The reason for this discrepancy could be due to differences in sample sizes, ethnic, racial and genetic factors.

In our study, we came across 2 patients of congenital external ear anomaly, one had isolated microtia and another had microtia $(2.86 \%)$ with unilateral EAC atresia $(1.43 \%)$ The main role of HRCT in EAC atresia is to identify the type of anomaly and determine the surgical correctability. If surgical correction of EAC atresia is to be done to improve hearing, normal inner ear structures and adequate middle ear cleft are mandatory. ${ }^{[19]}$

Identification of anatomical variations in some of the diseased ear proved to be beneficial for the ENT surgeons in successful completion of the surgeries. Korner's Septum [Figure 1] is an anatomic boundary formed by the petrosquamous suture which separates the squamous air cells from the petrous air cells. ${ }^{[20]}$ We had total 5 cases of pathological temporal bones having Korner's septum and all cases subsequently underwent surgery. The ENT surgeon had the preoperative information about the presence of Korner's septum which came out to be beneficial in all 5 cases (4 cases operated for suppurative middle ear disease and 1 case operated for Mondini malformation and received cochlear implant). The prevalence of Korner's septum shows no significant correlation $(p>0.05)$ with any temporal bone pathology. However it has a clear surgical importance as it must be removed to enter the mastoid antrum.

Facial nerve dehiscence is defined as loss of continuity in the bony structure of the fallopian canal producing abnormal communication between the middle ear space or mastoid air cell system and facial nerve canal. ${ }^{[20]}$ In 2 cases of cholesteatoma we found evidence of facial nerve dehiscence (FND) on preoperative CT imaging. This information guided the ENT surgeon to carefully dissect neighbouring structures of the facial canal during mastoidectomy. Cautious intra-operative monitoring of facial nerve is mandatory to reduce iatrogenic facial nerve injury. In above mentioned cases, there was presence of labyrinthine fistula (an abnormal communication between middle ear and fluid filled space of the inner ear). The preoperative identification of this fistula is most useful in terms of patient counseling and in removing the disease from the lateral semicircular canal so as to avoid sensorineural hearing loss.

High-riding jugular bulb (HRJB) has been variably defined as a jugular bulb that rises to the level of the basal turn of the cochlea, to the level of the superior tympanic annulus, or within $2 \mathrm{~mm}$ of the internal auditory canal (IAC). When there is deficient sigmoid plate, the jugular bulb protrudes into the middle-ear cavity, and is then known as a "dehiscent jugular bulb".[21-23] Two cases of suppurative middle ear disease in our study in which high jugular bulb [Figure 2], was noticed on CT imaging underwent mastoid exploration. Use of micromotor drill/ sharp instrumentations should be carefully done under high resolution to avoid injury to jugular bulb and brisk bleeding. The ENT Surgeon was most careful at the time of disease clearance and raising of flap around the tympanic annulus area during surgery.

We found one case of Foramen Tympanicum in a patient with left sided cholesteatoma. This finding turned out to be incidental on preoperative CT imaging. However, it did not affect the surgeon's approach to operate the cholesteatoma. Limitations of our study: Our study had small sample size which may limit statistical significance.This study comprised of predominantly younger population, so the findings of this study might vary with inclusion of elderly population in any other study with different age profile.

\section{Conclusion}

Common pathologies of temporal bones such as otomastoiditis and cholesteatoma which are otherwise difficult to assess clinically or on conventional radiography can be reliably evaluated on HRCT temporal bone. HRCT can accurately help in identification of various normal anatomical variations of ear with surgical significance preoperatively, thereby helping surgeons in planning surgical roadmaps and avoiding complications. HRCT allows precise assessment of inner ear status and thus helps in recognition of inner ear pathologies and malformations. Thus HRCT continues to stay as gold standard for evaluation of ear pathologies and anatomical variations.

References

1. Anbarasu A, Chandrasekaran K, Balakrishnan S. Soft tissue attenuation in middle ear on HRCT.Indian J Radiol Imaging 2012;22(4):298-304

2. Chintale SG, Kirdak VR, Jatale SP, Shaikh K. Correlation of HRCT mastoid with clinical presentation and operative findings in ear diseases. Int J Otorhinolaryngol Head Neck Surg 2017;3:656-660.

3. Karaca CT, Toros SZ, Noseri HK. Analysis of anatomic variations in temporal bone by radiology. IntAdvOtol 2012;8:239-43.

4. Handi PS, Patil MN, Nisha P. High resolution computed tomography of temporal bone in the evaluation of otologic diseases. Int $\mathrm{J}$ Otorhinolaryngol Head Neck Surg 2018;4.

5. Thukral CL, Singh A, Singh S, Sood AS, Singh K. Role of High Resolution Computed Tomography in Evaluation of Pathologies of Temporal Bone. J ClinDiagn Res 2015;9:7-10.

6. Bagul M. High-resolution Computed Tomography Study of Temporal Bone Pathologies. Int J Sci Stud 2016;4:60-65.

7. Tak J, Khilnani AK. Role of high resolution computed tomography of temporal bone in management of chronic suppurative otitis media. Int J Otorhinolaryngol Head Neck Surg 2016;2:193-196.

8. Hegde MC, Kamath MP, Shreedharan SS, Kumar N, Kumar A, Chandra S. A study of mastoid cellularity and middle ear diseases. Indian J Otol 2004;10:6-9.

9. Gans H, Wlodyka J. Mastoid pneumatization in chronic otitis media. Arch Otolaryngol 1966;83:343.

10. Sethi A, Singh I, Agarwal AK, Sareen D. Pneumatization of mastoid air cells: role of acquired factors. Int J Morphol 2006;24:35-38.

11. Karakas S, Kavakli A. morphometric examination of the paranasal sinuses and mastoid air cells using computed tomography. Ann Saudi Med 2005;25:41-45.

12. Lacouta A, Marsot-Dupucha K, Smoker WRK, Lasjauniasa P. 
Foramen tympanicum, or foramen of huschke: Pathologic cases and anatomic CT study. Am J Neuroradiol 2005;26:1317-1323.

13. Vallabheneni R, Srinivasa BCR. HRCT Temporal Bone Findings in CSOM: Our Experience in Rural Population of South India. IOSR Journal of Dental and Medical Sciences 2016;15: 49-53.

14. Kumaresan S, Nirmala M. Usefulness of pre-operative high-resolution computed tomography in middle ear cholesteatoma. International Journal of Scientific Study 2017;5:249-251.

15. Jackler RK, Luxford WM, House WF. Congenital malformations of the inner ear: a classification based on embryogenesis. The laryngoscope 1987;97:2-14.

16. Sennaroglu L, Saatci I. A New Classification for Cochleovestibular Malformations. The laryngoscope 2003;112:2230-2241.

17. Joshi VM ,Navlekar SK, Kishore GR, Reddy KJ, Kumar ECV. CT and MR imaging of the inner ear and brain in children with congenital sensorineural hearing loss. Radiographics 2012;32:683-698.

18. Wu WJ, He XB, Tan LH, Peng HU, Peng AQ, Xiao ZA, et al. Imaging assessment of profound sensorineural deafness with inner ear anatomical abnormalities. Journal of Otology 2015;10:29-38.

19. Eelkema EA, Curtin HD. Congenital anomalies of the temporal bone. Semin Ultrasound CT MR 1989;10:195-212.

20. Goksu N, Kemaloglu YK, Koybasioglu A, Ileri F, Ozbilen S, Akyildiz N. clinical importance of the Korner's septum. Am J Otol 1997; 18:304-6.

21. Rauch S D, Xu W 7., Nadol J B Jr. High jugular bulb: implications for posterior fossa neurotologic and cranial base surgery. Ann Otol Rhinol Laryngol 1993;102:100-7.

22. Wadin K, Thomander L, Wilbrand H. Effects of a high jugular fossa and jugular bulb diverticulum on the inner ear. A clinical and radiologic investigation. Acta Radiol Diagn 1986;27:629-36.

23. Hourani R, Carey J, Yousem D M. Dehiscence of the jugular bulb and vestibular aqueduct: findings on 200 consecutive temporal bone computed tomography scans. J Comput Assist Tomogr 2005;29:65762 .

Copyright: (C) the author(s), publisher. Asian Journal of Medical Radiological Research is an Official Publication of "Society for IIealth Care \& Research Development”. It is an open-access article distributed under the terms of the Creative Commons Attribution Non-Commercial License, which permits unrestricted non-commercial use, distribution, and reproduction in any medium, provided the original work is properly cited.

How to cite this article: Kumar L, Malhotra A, Rastogi R, Pratap V. Analytical Study of Temporal Bone Pathologies and Anatomical Variations on High Resolution CT. Asian J. Med. Radiol. Res. 2019;7(1):20-25.

DOI: dx.doi.org/10.21276/ajmrr.2019.7.1.5

Source of Support: Nil, Conflict of Interest: None declared. 